walk across a small cottage kitchen, and after taking it three weeks she walked a distance of two miles to see me, with comparative ease. Was the milk obtained by Dr. Barclay pure?

Your obedient servant,

Norwich, May, $1873 . \quad$ T. H. ColmaN, M.R.C.S.E.

\section{THE INSIDIOUS EFFECTS OF THE HYDRATE OF CHLORAL.}

To the Editor of The LaNCET.

SrR,-In your issue of the 10th inst., you ask members of the profession to give information on the insidious action of the hydrate of chloral.

About three years ago I had a good deal of experience of this substance, but the subject of it being a near relative, I did not care about it being made public; neither do $I$ now, but if any of my observations are of use, you may use them as you please, withholding my name and address.

My patient was my wife's sister, aged thirty, of sanguine temperament. She suffered at times from severe attacks of angina pectoris, though, in common with many medical men she had consulted, I could find no disease of the heart. It seemed rather smaller than natural. Several years before I knew her she had a miscarriage, and the flooding consequent on this nearly cost her her life. Since that time she had travelled from one medical man to another, submitting to experiments of one kind and another in the hope that she might become pregnant. In this, however, she was disappointed. Finally, she came under the treatment of the late Sir James Simpson, who took a great interest in her. This interest was intensified when she told him what a naturally powerful antipathy to sleep she had, and that she was a somnambulist. This last condition caused her to perform an extraordinary freak one night. She got out of bed at 1 A.M., partially dressed herself, went down stairs, and, followed by one of her dogs, let herself out. She then walked or ran two miles to the cemetery where her father is buried, and woke herself shaking the gates. Of course this gave her a dreadful fright, especially as she was pursued by a man on the way home. When she told me of this performance next morning I could scarcely credit it until she showed me the clothes she had worn. This narrative redoubled Sir James Simpson's notice of her, and he prescribed the hydrate of chloral in doses of forty grains at bedtime. This was used occasionally, but an attack of oraritis supervening, it had to be used every night. At that time chloral was not known in the neighbourhood, and at considerable cost it was procured from Edinburgh. A curious feature in my patient's case increased the expense. After the first dose, whether we gave it all or in part, she always was sick, so that a double dose was used every night. I have noticed this in three other cases. The effect of the drug was almost instantaneous. She would go to sleep in two, three, or at most five minutes, even if she had an attack of angina. She slept quietly, and always expressed herself as quite refreshed in the morning. After the dose, her pulse, generally small and 80 per minute, would fall from ten to twelve beats; it would, after the lapse of half an hour or so, rise to 90 and even 100, and then, after some time, fall to its normal state. It was hard, but regular. Her respiration was quiet, and at times imperceptible. After a time, forty grains were useless, and an additional twenty were added. This in course of time gave way to eighty, and one night I remember giving within twelve hours 120 grains. This would probably be four months after the commencement of the chloral. By that time she had passed into a most unhappy condition. From having been a woman of strong will and excellent mental power she became listless and peevish-childish indeed in many things, begging for chloral, conjuring us all of our charity to give her a dose, and even offering rewards to the nurse (who had been ordered not to touch the medicine) if she would give her a double dose. Indeed, this madness grew on her so much that when the room was left for a moment one day she got out of bed, and fell in trying to get to the bath-room where the chloral bottle was kept. In fact, towards the end of her life her chief thought was how much chloral she would get at night. She was seized with diar. rhoa about two months before she died, produced, I fear, by the chloral. During this diarrbca she passed a large amount of gelatinous matter in the stools. It was held in check by charcoal and astringent enemata for some time, but she finally succumbed to it.

Taking this case, for I have never (though I have used chloral repeatedly) permitted it to be pushed to this extent, I have come to the conclusion that, as a temporary hypnotic, it is, as a rule, excellent, but that by keeping it up constantly it requires increased dose, and surely depreciates the mental and bodily tone.

I am, Sir, your obedient servant,

Stoke-on-Trent, May 18th, 1873.

ANTI-CHLORAL.

\section{To the Editor of THY LANCET.}

SrR,-I have used chloral in different cases of mania, but have not found much benefit from it in acute cases. The cases I find chloral suit best are those of nervous depression, when the patient is not able to sleep at night. I usually begin with a draught at bedtime, composed of twenty-five grains of chloral, twenty minims of tincture of hyoscyamus, and one ounce of water, and gradually increase the dose up to two scruples of chloral and forty minims of hyoscyamus, and $I$ have used this dose in case of want of rest from nervous depression for three months without any illeffects, but gaining for the patient a good night's rest, and have never had any head symptoms arise from the use of chloral. The only difficulty that I found was, when I had begun the chloral, how to leave it off, as in these cases the patients dread going to bed without a draught; so the way I found to act best was to decrease the dose as the patient got better, and I found this answer very well. In one case of nervous depression, in a patient who suffered from religious delusions and could not sleep at night-in fact, he said he had been taking chloral for some time before he came under my notice,-I tried him one or two nights without the draught, and he never slept a bit. He then took the draught every night for two months. His mental condition now much improved, and the only thing was, he could not sleep at night. He was very desirous of getting home, and I told him he could not be well while he was taking a draught at bedtime, so he agreed to have his draught with him, but not to take it for two hours every night, and then only a sip out of the bottle. This answered very well, and in a week's time he could sleep satisfactorily. From my little experience I have great faith in chloral in these cases.

Yours obediently,

SrDNer OIIve Brshop, M.R.C.S.E., L.R.C.P.ED., May, 1873. Resident Medical Officer, Fisherton Asylum, Salisbury.

\section{HOSPITAL OUT-PATIENT REFORM. To the Editor of THE LANCET.}

SrR,-The question of out-patients at our hospitals is one which greatly affects the interests of the really deserving poor, as well as the body of general practitioners. It is, therefore, not one to be dismissed by off-hand statements. In The Lancer of the 3rd instant you express a wish to have some facts given as to persons who should not have applied to hospitals for medicine and advice. I will, therefore, supply you with the initials of half a dozen persons, with their position, who have applied and have been admitted as out-patients to hospitals.

D-, a Custom-house officer, living in his own house, possessed of other means, and with a salary of between $£ 200$ and $£ 300$ a year.

F-C, the owner of not less than thirty houses.

$\mathrm{H}-$, a buyer in a wholesale city lace warehouse.

$\mathrm{H}-$ _ collector for a water company, whose commission was about $\$ 400$ per annum; also owner of house property.

$\mathrm{U}-$, buyer for a wholesale city house, carrying on also a profitable retail shop, employing several assistants, and whose income could not be less than $\$ 1000$ per annum.

Wfare of a respectable suburb, with a flourishing business. 